\title{
Refinement of the Messinian APTS from sedimentary cycle patterns in the lacustrine Lava section (Servia Basin, NW Greece)
}

\author{
J. Steenbrink ${ }^{\mathrm{a}, *}$, N. van Vugt ${ }^{\mathrm{b}}$, M.L. Kloosterboer-van Hoeve $^{\mathrm{c}}$, F.J. Hilgen ${ }^{\mathrm{a}}$ \\ a Department of Geology, Faculty of Earth Sciences, Utrecht University, Utrecht, The Netherlands \\ b Palaeomagnetic laboratory 'Fort Hoofddijk', Faculty of Earth Sciences, Utrecht University, Utrecht, The Netherlands \\ c Laboratory of Palaeobotany and Palynology, Faculty of Biology, Utrecht University, Utrecht, The Netherlands
}

Received 1 April 2000; received in revised form 5 June 2000; accepted 5 June 2000

\begin{abstract}
A high-resolution cyclostratigraphy and magnetostratigraphy is presented for the Messinian lacustrine Lava section from the Servia Basin in NW Greece, constraining more precisely the absolute ages of magnetic polarity subchrons C3An.1n and C3An.2n. The section contains 15 distinct sedimentary cycles of alternating dark- and light-coloured marls, while the gamma-ray attenuation record reveals an additional five to six cycles. The cycles in the lower half of the section are on average $5.3 \mathrm{~m}$ thick, as opposed to the cycles in the upper part, which have an average thickness of $3.1 \mathrm{~m}$. Palynological results define the lithological alternations in both the lower and upper cycles in terms of periodic changes in humidity, where the light marls represent the humid periods and the dark marls the relatively dry periods. Changes in cycle thickness and shifts in average gamma-ray values suggest a rather abrupt decrease in sedimentation rate at $\sim 60 \mathrm{~m}$ in the section. This is confirmed by the magnetostratigraphy, which recorded four reversals, which - given the biostratigraphic constraints from the Lava locality - could be correlated unambiguously to subchrons C3An. In and $\mathrm{C} 3 \mathrm{An} .2 \mathrm{n}$ of the geomagnetic polarity time scale. With this magnetostratigraphic time control, the average duration of the cycles can be calculated to be constant in the entire section, and similar to precession. The astronomical origin of the cycles is confirmed by the results of spectral analyses of gamma-ray and susceptibility time series. The sedimentary cycles in the upper part of the Lava section are unambiguously tuned to insolation using the typical clustering of the cycles that follows the eccentricity cycle. The filtered gamma-ray record centred at $41 \mathrm{kyr}$ confirms the tuning in the upper part and allows tuning of the lower part. The tuning results in accurate ages for the sedimentary cycles and polarity reversals that confirm the astronomical tuning of [Krijgsman et al., Nature 400 (1999) 652-655], but define more precisely the astronomical polarity time scale. (C) 2000 Elsevier Science B.V. All rights reserved.
\end{abstract}

Keywords: lake sediments; Greece; Messinian; sedimentation; cyclic processes; magnetostratigraphy; palynology; eccentricity

\section{Introduction}

The astronomical theory of climate change, ac-

* Corresponding author. Tel.: +31-30-253 5125;

Fax: +31-30-253 5030; E-mail: jsteen@geo.uu.nl cording to which climatic oscillations are linked to perturbations in the Earth's orbit [2], is at 
present widely accepted. During the last decades, deep-sea oxygen isotope records have convincingly demonstrated that Pleistocene glacial cycles are driven by orbitally controlled variations in solar radiation [3-6]. More recently, the recognition of Milankovitch cycles in sedimentary records of especially marine deposits has enabled the development of very accurate time scales for the entire Neogene marine record. In combination with magnetostratigraphy this has resulted in the development of an astronomically polarity time scale (APTS) [7-10]. For the Messinian, the first attempts for the construction of an APTS using astronomical tuning was in the Bou Regreg section in Morocco [11]. Currently, the APTS is based on the integrated stratigraphy of several marine sections in the Mediterranean [1]. The astronomical tuning of these sections is confirmed by open-ocean calcareous nannofossil biochronology from ODP sites 853 and 926 and by their implications for sea-floor spreading rates (see [1], Table 1). The magnetostratigraphic data were de- rived from the Spanish Sorbas Basin [1] and the Cretan Faneromeni section [12]. Because of the moderate quality of the palaeomagnetic signal in these sections, the astronomical ages of the polarity reversals in the APTS are not well constrained (uncertainties of 20 to $60 \mathrm{kyr}$ ).

Evidently, orbital forcing influences not only marine, but also continental sediments. The best known example of orbital forced sedimentary cyclicity is the Triassic lacustrine succession of the Newark Basin [13,14]. Long and continuous cyclically bedded continental successions are also present in the Mediterranean area. Recent studies demonstrated a strong orbital control on sedimentation for Late Miocene marginal lacustrinefloodplain sequences in the Calatayud Basin in Spain [15], for Lower Pliocene lignite-marl alternations in the Ptolemais Basin in northern Greece $[16,17]$, and for Middle Pleistocene lignite seams in the Megalopolis Basin [18].

In this paper, we present the results of an integrated study on the cyclically bedded Messinian

Table 1

Age models, sedimentation rates and cycle periods for the Lava section

\begin{tabular}{|c|c|c|c|c|c|c|c|c|}
\hline Reversal & Position & $\begin{array}{l}\text { This study } \\
\text { APTS age }\end{array}$ & $\begin{array}{l}\text { KRIJ99 } \\
\text { SR age }\end{array}$ & & $\begin{array}{l}\text { KRIJ99 } \\
\text { APTS age }\end{array}$ & & $\begin{array}{l}\text { CK95 } \\
\text { GPTS age }\end{array}$ & \\
\hline C3An.1n(o) & $120.1 \pm 0.8$ & $6.273 \pm 0.005$ & 6.28 & & $6.26 \pm 0.02$ & & 6.137 & \\
\hline C3An.2n(y) & $96.4 \pm 0.1$ & $6.433 \pm 0.001$ & 6.43 & & $6.44 \pm 0.01$ & & 6.269 & \\
\hline C3An.2n(o) & $44.2 \pm 1.4$ & $\begin{array}{l}6.699 \pm 0.005^{*} \\
6.731 \pm 0.010^{*}\end{array}$ & 6.73 & & $6.71 \pm 0.03$ & & 6.567 & \\
\hline Polarity interval & Length & Cycle thickness & Duration & Sed rate & Duration & Sed rate & Duration & Sed rate \\
\hline C3An.1r & $23.6 \pm 0.9$ & $3.1 \pm 0.8$ & 150 & $0.16 \pm 0.01$ & $180 \pm 22$ & $0.13 \pm 0.02$ & 132 & $0.18 \pm 0.01$ \\
\hline C $3 \mathrm{An} .2 \mathrm{n}$ & $52.3 \pm 1.4$ & $4.3 \pm 1.0$ & 300 & $0.17 \pm 0.01$ & $270 \pm 32$ & $0.19 \pm 0.02$ & 298 & $0.18 \pm 0.01$ \\
\hline Polarity interval & Length & Cycle thickness & Sed rate & Period & Sed rate & Period & Sed rate & Period \\
\hline C3An.1r & 23.3 & $3.1 \pm 0.8$ & $0.16 \pm 0.01$ & $19.9 \pm 5.4$ & $0.13 \pm 0.02$ & $23.8 \pm 7.1$ & $0.18 \pm 0.01$ & $17.5 \pm 4.8$ \\
\hline $\begin{array}{l}\text { C3An.2n (from } \\
60 \mathrm{~m} \mathrm{up} \text { ) }\end{array}$ & 36.4 & $3.6 \pm 0.5$ & $0.16 \pm 0.01$ & $23.0 \pm 3.1$ & $0.13 \pm 0.02$ & $27.6 \pm 5.0$ & $0.18 \pm 0.01$ & $20.2 \pm 2.7$ \\
\hline $\begin{array}{l}\text { C3An.2n (from } \\
60 \mathrm{~m} \text { down) }\end{array}$ & 15.9 & $5.3 \pm 0.5$ & $0.23 \pm 0.04$ & $22.8 \pm 4.0$ & -2.2 & - & $0.17 \pm 0.02$ & $31.3 \pm 4.7$ \\
\hline
\end{tabular}

Upper panel: Palaeomagnetic age models for the Lava section. Position $(\mathrm{m})$ of reversal horizons in the Lava section and ages (Ma) of the corresponding reversals based on spreading rates (SR) and astronomical tuning (APTS) [1], and sea-floor anomalies (GPTS) [33]. The error estimates in the astronomical reversal ages refer to the uncertainty in the stratigraphic position of the reversal with respect to the astronomically dated cycles only, not taking into account errors arising from tuning. Asterisks correspond to the two astronomical ages for C3An.2n(o), related to the two correlation options (Fig. 6). Middle panel: Length (m) of the polarity intervals and average cycle thickness $(\mathrm{m})$ within these intervals. Duration $(\mathrm{kyr})$ and average sedimentation rate $(\mathrm{m} /$ kyr) in these intervals according to the different time scales. Note the difference in sedimentation rate between the two polarity intervals for both the SR and APTS time scales. Lower panel: As middle panel, with the sedimentation rate from subchron C3An.1r extrapolated down to $60 \mathrm{~m}$. Note the similarity of the average cycle periods and the period of precession for the SR age model, and divergent periods for the other age models. 


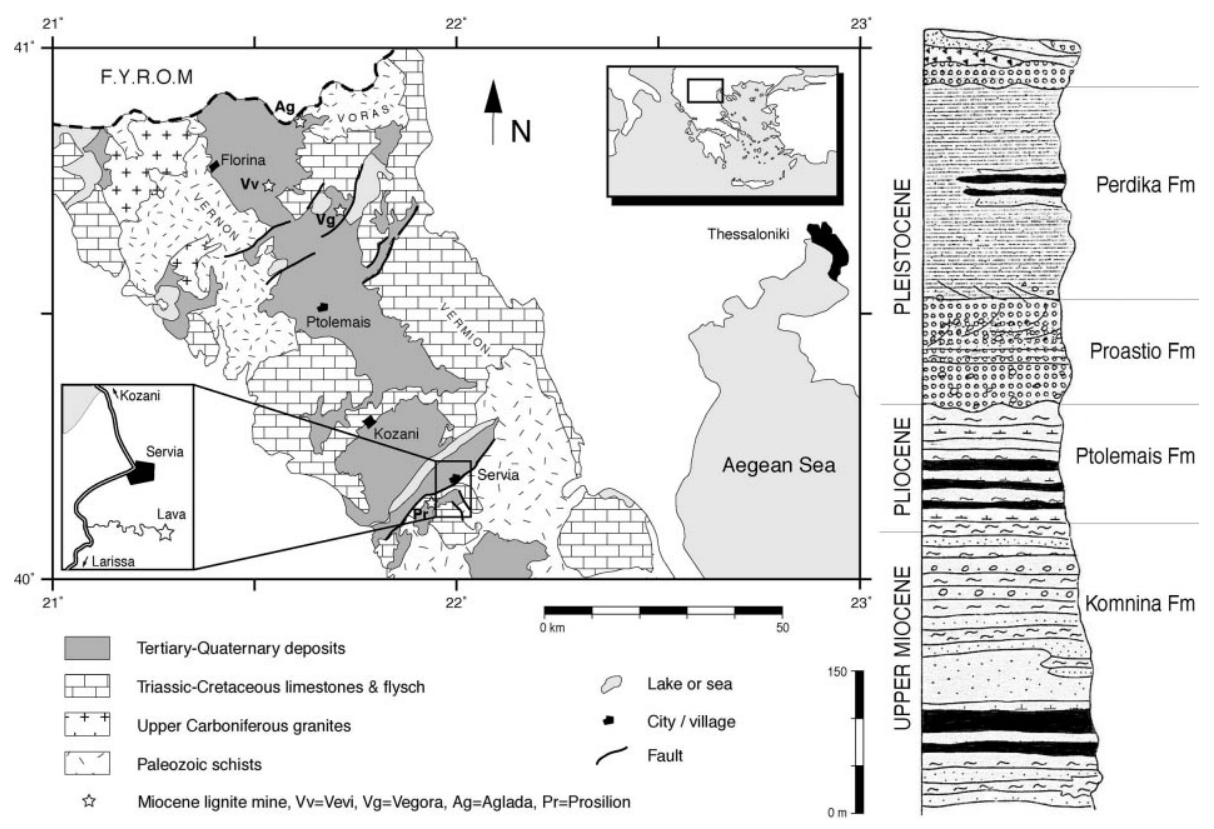

Fig. 1. Geological map of the Florina, Ptolemais and Servia Basins. F.Y.R.O.M. is the Former Yugoslav Republic of Macedonia. The inset shows the location of the Lava mine. Sketched stratigraphic column of the basin fill after [19].

lacustrine Lava section from the Servia Basin, NW Greece. Astronomical tuning of the sedimentary cycle pattern combined with a reliable magnetostratigraphy offers a unique opportunity to confirm and define more precisely the APTS ages in the Messinian.

\section{Geological setting}

The intramontane lignite-bearing Servia Basin is located approximately $100 \mathrm{~km}$ southwest of Thessaloniki and is part of an elongated NNW-SSE trending graben system that extends over a distance of $120 \mathrm{~km}$ from Bitola in the Former Yugoslav Republic of Macedonia (F.Y.R.O.M.) to Servia in northern Greece (Fig. 1). The graben system developed in the Pelagonian Zone (the westernmost zone of the Internal Hellenides [20]) in response to Late Miocene NE-SW extension [21]. A Pleistocene episode of NW-SE extension resulted in the development of several basins, including the basins of Florina, Ptolemais and Servia [21]. The basins are flanked by mountain ranges that are primarily composed of Mesozoic limestones, Upper Carboniferous granites and Palaeozoic schists [20] (Fig. 1). The basin fill comprises a $\sim 600 \mathrm{~m}$ thick Late Miocene to Late Pleistocene succession of predominantly lacustrine sediments with intercalated lignite seams and fluvial deposits, which can be divided into a number of basin-wide lithostratigraphic units [22,23] (Fig. 1).

In this study, we focus on a part of the lower Komnina Formation, which was dated as Late Miocene (Turolian, lower part of mammal zone MN 13) on the basis of small mammals (Apodemus sp. 3) [24], plant remains [25] and charophytes [26]. The Komnina Formation is $\sim 300$ $\mathrm{m}$ thick; it unconformably overlies the pre-Neogene basement and is predominantly composed of fluvial sands and conglomerates, and lacustrine (diatomaceous) marls and clays, with some intercalated lignite seams. This information is mainly derived from drillings and from outcrops in openpit lignite mines in the Florina Basin (Achlada and Vevi mines), Ptolemais Basin (Vegora mine) and Servia Basin (Lava and Prosilion mines) (Fig. 1). 


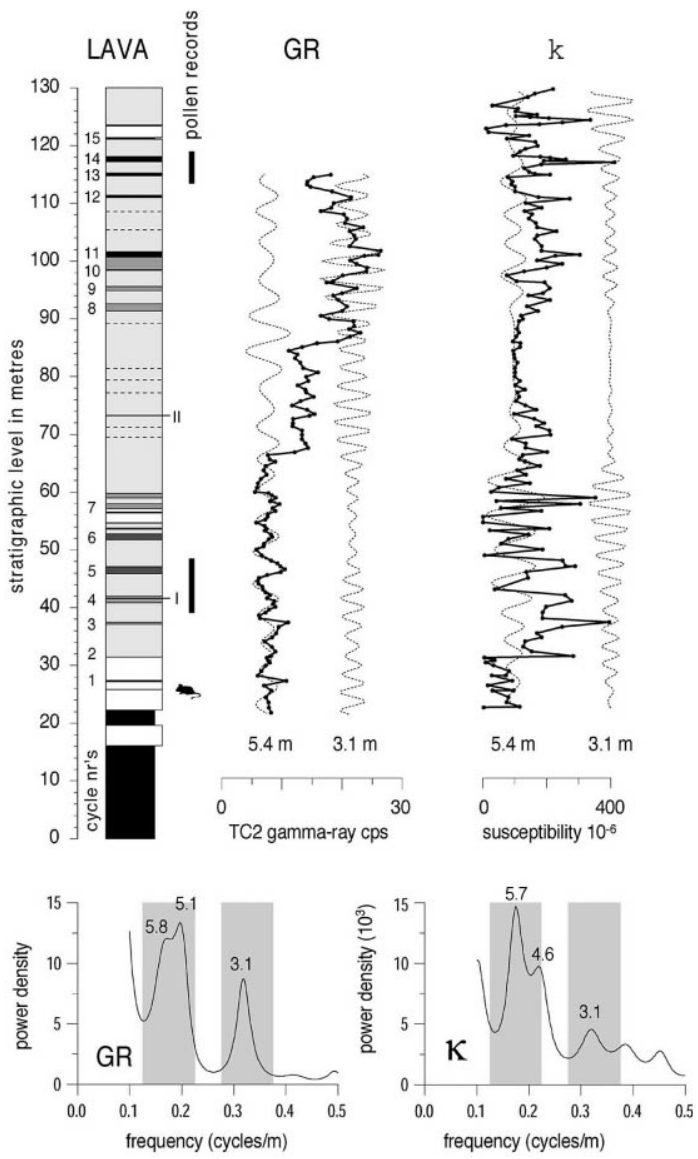

Fig. 2. Top: Schematic lithological column of Lava with sedimentary cycle numbers: black indented $=$ lignite, white $=$ carbonate, light shaded = marl, intermediate (dark) shaded=dark (-er) marl, black=clay. I and II denote key beds; mouse denotes level with small-mammal fauna [24] and vertical lines indicate the position of the two palynological records. Dashed lines indicate thin dark marl beds. Gamma-ray and magnetic susceptibility records with their filtered components (dashed lines) in the depth domain. Bottom: Maximum entropy variance spectra of the GR (187 data points, length of filter is $16.6 \%$ of the series) and $\kappa$ records (215 data points, length of filter is $14.9 \%$ of the series), computed with the Analyseries program [27], investigated in the frequency range 0.1 to $0.5 \mathrm{cycle} / \mathrm{m}$. The Blackman-Tuckey and Multi Taper Method yielded comparable results (not shown). The cycle length $(\mathrm{m})$ is indicated; the shaded bands indicate the bandwidths of the 5.4 and $3.1 \mathrm{~m}$ filters.

\section{Studied section and sampling}

The Lava section is exposed in a private openpit lignite mine, situated a few kilometres south of Servia and close to the deserted village of Lava (Fig. 1) in the footwall block of a major fault system that runs ENE-WSW and forms the southern margin of the Servia Basin. We selected the Lava mine for this study for a number of reasons. It has the most complete succession of the Komnina Formation. The sediments that crop out in the Lava mine display a distinct sedi- mentary cyclicity and, in contrast to some of the other mines, are all fine-grained, which is preferred for our palaeomagnetic study. Moreover, a biostratigraphic age constraint to calibrate these palaeomagnetic data is provided by a fossiliferous level with small mammal remains [24].

The Lava section has a thickness of $130 \mathrm{~m}$ (Fig. 2). The basal $\sim 20 \mathrm{~m}$ of the section contain two (xylite-type) lignite seams, which are separated by homogeneous clays and laminated marls with abundant charophyte oogonia and freshwater gastropods. The upper $\sim 110 \mathrm{~m}$ consist mainly of 
lacustrine marls and clays with abundant leafs (among which the characteristic Late Miocene Glyptostrobus europeus [28]), freshwater diatoms and ostracods, and show a distinct cyclicity. Rather abrupt changes towards more clayey and organic-rich sediments occur twice in the lithology, namely between 60 and $67 \mathrm{~m}$ and between 85 and $88 \mathrm{~m}$ in the section. At $41.6 \mathrm{~m}$, a $5 \mathrm{~cm}$ thick bed full of gastropods is found (key bed I) and at $73.2 \mathrm{~m}$, a $5 \mathrm{~cm}$ thick clay inter-bed yielded abundant fish teeth and vertebrae (key bed II). These two key beds have a constant thickness over the entire mining area and were also recognised in the $5 \mathrm{~km}$ westerly situated Prosilion mine, which supports their potential use as marker beds.

Detailed logging and sampling of the Lava section was done in two campaigns. In 1994 the section was logged and sampled from the base up to $115 \mathrm{~m}$, an upward extension was done in 1997. We took oriented palaeomagnetic samples, cored with a portable drill at 194 levels over a stratigraphic interval of $130 \mathrm{~m}$, which corresponds to an average spacing of $67 \mathrm{~cm}$. Additional non-oriented samples were taken at the same levels for chemical and pollen analyses. During the 1994 sampling campaign, the gamma-ray signal was measured seven-fold at each sampling level with a UG135 differential gamma spectrometer. Data were measured in the TC2-mode, detecting all energies above $400 \mathrm{kea}$. The low-field bulk magnetic susceptibility of the samples was measured in the laboratory on a KLY-2 susceptibility bridge. The natural remanent magnetisation (NRM) was studied in the laboratory by means of standard stepwise thermal demagnetisation procedures and measured on a 2 G DC SQUID magnetometer.

\section{Cyclostratigraphy of the Lava section}

The lacustrine succession that constitutes the upper $\sim 110 \mathrm{~m}$ of the Lava section is composed of alternating light- and dark-coloured marls on various scales. The dark-coloured marl beds are faintly laminated and enriched in organic matter and/or clay. The light-coloured marl beds are homogeneous and enriched in carbonate. The most prominent colour variations occur on a scale of 3 to $5 \mathrm{~m}$. A basic sedimentary cycle is defined as one such 3-5 m thick dark-light marl couplet. The distinct dark marl beds, which we defined as the base of a sedimentary cycle, are numbered in ascending order from the base of the Lava section upward. Faintly developed (or very thin) dark-coloured marl beds are also present in various parts of the section (see below), but these were not numbered.

The Lava section contains 15 distinct sedimentary cycles. These cycles are not present throughout the entire section, but are found in two intervals. The first interval forms the lower part of the marl succession, it starts from $\sim 20 \mathrm{~m}$ in the section, just above the second lignite, and continues up to $\sim 60 \mathrm{~m}$ in the section. It contains seven regular cycles (cycles 1-7) of alternating darkand light-coloured marl beds, which have an average thickness of $5.1 \pm 0.7 \mathrm{~m}$. The dark-coloured marl bed of cycle 5 is the most prominent one in this interval. Within the light-coloured marl beds of cycle 6 , which is very carbonate-rich and distinctly yellowish-coloured, two additional thin dark-coloured marl beds are present. The darkcoloured marl bed of cycle 7 is composed of one thin, and two thicker dark-coloured marl beds (Fig. 2).

The second interval is found in the upper part of the section, between roughly 90 and $120 \mathrm{~m}$ and contains eight cycles that are arranged in two clusters. The lower cluster comprises four well-developed cycles (cycles 8-11), with an average thickness of $3.3 \pm 0.6 \mathrm{~m}$. Especially the dark marl beds of cycles 10 and 11 are very distinct and clay-rich. The upper cluster contains four sedimentary cycles (cycles 12-15), of which the three lower cycles (cycles 12-14) are very regular, both in thickness $(\sim 3.3 \mathrm{~m})$ and appearance, and have prominent dark-coloured clay beds. Cycle 15 is relatively thin $(2.3 \mathrm{~m})$; its dark marl bed is strongly lignitic and the light marl segment of this cycle contains abundant freshwater gastropods and is composed almost exclusively of carbonate. In between the two clusters of the second interval lies a more homogeneous interval in which a few $\mathrm{cm}$ thick dark-coloured clay beds are intercalated: four at around $105 \mathrm{~m}$ and one 
at around $108 \mathrm{~m}$, suggesting that two more cycles might be present in this interval (Fig. 2).

The two intervals with well-developed sedimentary cycles are separated by an interval, which runs from $\sim 60$ to $90 \mathrm{~m}$ in the section and lacks an obvious lithological cyclicity. This interval is not homogeneous, but the difference between the dark- and light-coloured marl beds is less pronounced. This makes subdivision into sedimentary cycles arbitrary. There are a few prominent dark-coloured marl beds, but these are very thin $(<10 \mathrm{~cm})$ and not regularly spaced (Fig. 2).

\section{Gamma-ray and susceptibility}

The gamma-ray intensity and low-field magnetic susceptibility records of the Lava section were measured to quantify the subtle light-dark colour variations that we observed in the field. Moreover, spectral analysis of these records in either the depth or time domain enables an objective estimate of periodic characteristics. The gamma-ray (GR) intensity is mainly a function of the Uranium content [29]; Uranium tends to be more abundant in both detrital minerals and organicrich sediments. The low-field susceptibility $(\kappa)$ is positively influenced by the concentration of ferrimagnetic and paramagnetic (clay) minerals and negatively by diamagnetic material (carbonate). Both gamma-ray and susceptibility are thus good parameters to describe the alternation of organic-rich clay layers and carbonate-rich marl layers.

The GR and $\kappa$ records are marked by a high variability showing a close correlation with the lithological variation (Fig. 2). More precisely, they reveal relatively high values in the dark-coloured clay-rich beds and low values in the lightcoloured carbonate-rich beds. The GR record reflects all sedimentary cycles as recognised in the field. In addition, the GR recorded another five or six minima and maxima in the interval between $\sim 60$ and $\sim 90 \mathrm{~m}$, where no distinct sedimentary cyclicity was observed. These maxima correspond to thin darker (clay) layers, which suggests that cyclicity is present in this interval as well, but less distinct than in the rest of the section. Sedimen-

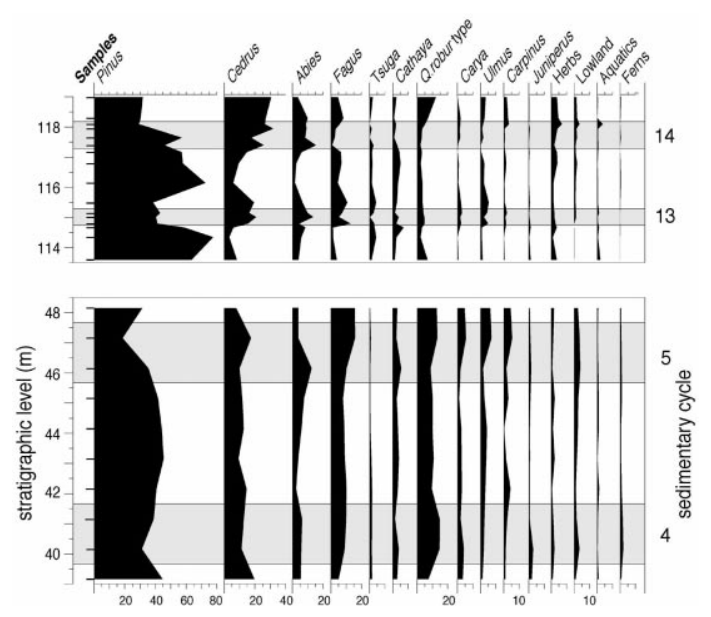

Fig. 3. Pollen diagram of cycles 4, 5, 13 and 14 from Lava. The results are presented as percentages of a pollen sum including all pollen and spores, excluding fungi and algae. The grey bands indicate dark marls. Herbs are a sum of mainly Poaceae, Asteraceae and Chenopodiaceae; Lowland consists of Taxodium and some Salix and Alnus; Aquatics are a sum of Cyperaceae, Nuphar and Ceratophyllum; Ferns are a sum of Polypodiaceae and Osmunda. Quercus robur type consists only of deciduous species of Quercus.

tary cycles $2-7$ and 9-16 can be recognised as peaks in the $\kappa$ record, but $\kappa$ does not show any regular minima and maxima in the non-cyclic interval. The GR record shows a much smoother curve than the $\kappa$ record, because $\kappa$ is measured on discrete samples, while the gamma spectrometer measures the GR intensity at the outcrop averaged over a $25 \mathrm{~cm}$ diameter. Two sharp increases in the mean GR value between 60 and $67 \mathrm{~m}$ and between 85 and $88 \mathrm{~m}$ co-occur with two earlier described lithological changes towards more clayey and organic-rich sediments. The $\kappa$ record, on the other hand, does not show any pronounced change in its mean value.

The variance spectra of the GR and $\kappa$ records in the depth domain show that power is concentrated in two broad bands (Fig. 2, bottom). One is centred at $\sim 5.4 \mathrm{~m}$ and the other at $\sim 3.1 \mathrm{~m}$. These two values are indistinguishable from the average cycle thickness in the lower and upper part of the section, which was calculated as $5.1 \pm 0.7$ and $3.3 \pm 0.6 \mathrm{~m}$, respectively. Further confirmation of cyclicity in both the GR and $\kappa$ records with periods close to those of the sedi- 
mentary cyclicity is given by applying a Gaussian bandpass filter to the GR and $\kappa$ records (centred at 5.4 and $3.1 \mathrm{~m}$ ). The filtered records centred at $5.4 \mathrm{~m}$ follow the GR and $\kappa$ records - and thus the lithological cyclicity - best in the lower half of the section, while the filtered records centred at $3.1 \mathrm{~m}$ reproduce the cyclicity best in the upper part of the section (Fig. 2). The shift from a dominantly $5.4 \mathrm{~m}$ scale cyclicity towards a $3.1 \mathrm{~m}$ scale cyclicity is especially obvious from the filtered GR record and occurs between 60 and $67 \mathrm{~m}$, coinciding with the first increase of the mean GR values.

\section{Palynology of sedimentary cycles}

We conducted a palynological study on 26 samples covering cycles 4 and 5, and cycles 13 and 14 from the lower part and upper part of the section, respectively (Fig. 2). Such a study enables us to interpret the lithological cyclicity in terms of changes in vegetation, from which changes in precipitation and/or temperature can be inferred.

During the four cycles investigated (Fig. 3), mixed deciduous/coniferous forests appear to have been widespread in the mid-altitude uplands surrounding the intramontane sedimentary basin. Montane forests with Pinus, Cedrus, Abies and Fagus dominated at higher elevations. Lowland elements, characteristic for fringing swamp vegetation around the lake, are mainly represented by Taxodium.

The palynological evidence points to continuously wet and warm-temperate climatic conditions. This is notably apparent from the records of conifer pollen. Cathaya presently occurs in mid-altitude forests in China where annual precipitation is in excess of $2000 \mathrm{~mm}$ [30]. Tsuga is nowadays restricted to mountainous regions in Asia and North America where similarly high precipitation occurs throughout the growing season [30]. An annual precipitation between 1000-1500 $\mathrm{mm}$ at higher altitudes can be inferred from the occurrence of Cedrus [30]. Cedrus forests nowadays occur only in high mountains around the eastern Mediterranean Basin. Humid warm-temperate conditions were also inferred from studies on macro-flora of the Lava mine [28]. Additional evidence that conditions may have been generally moister than at present is provided by the conspicuous absence of dry-tolerant sclerophyllous evergreen species of Quercus, characteristic of modern Mediterranean vegetation. The subordinate presence of Juniperus may have been controlled more by substrate than by (low) precipitation.

Superimposed on these generally wet conditions, palynological data for cycles 13 and 14 indicate periods of relatively increased precipitation that more or less coincide with the deposition of the light-coloured marls. Analogous to Holocene vegetation development in the eastern Mediterranean region [31], a marked spread of Pinus at the expense of Cedrus can be interpreted as an increase in precipitation at higher elevations, resulting in downward expansion of Pinus into the midaltitude deciduous forests. Similarly, increased montane humidity may also be responsible for an expansion of Fagus at the cost of Abies. The pollen spectra of cycles 4 and 5 have generally higher amounts of Fagus and Quercus relative to the upper cycles. This may be due to higher (winter) temperatures in the lower cycles. Cyclic changes in precipitation are less obvious in the pollen records of these lower cycles than in cycles 13 and 14, which is in agreement with the less pronounced lithological changes in these lower cycles. Apparently, climate was more equable during deposition of these lower cycles. Yet, careful inspection of the pollen curves suggests similar patterns for the relation between Pinus and Cedrus, as well as for Fagus and Abies. Palynological data of both the lower and upper cycles thus indicate that climate was generally humid and warm-temperate, but cyclic changes in precipitation seem to have occurred. Periods with increased precipitation occurred during deposition of the light marls, in the lower, as well as in the upper cycles.

\section{Palaeomagnetic analysis}

We used magnetostratigraphy in combination with small mammal biostratigraphy [24] to con- 


\section{SR time scale \\ LAVA}
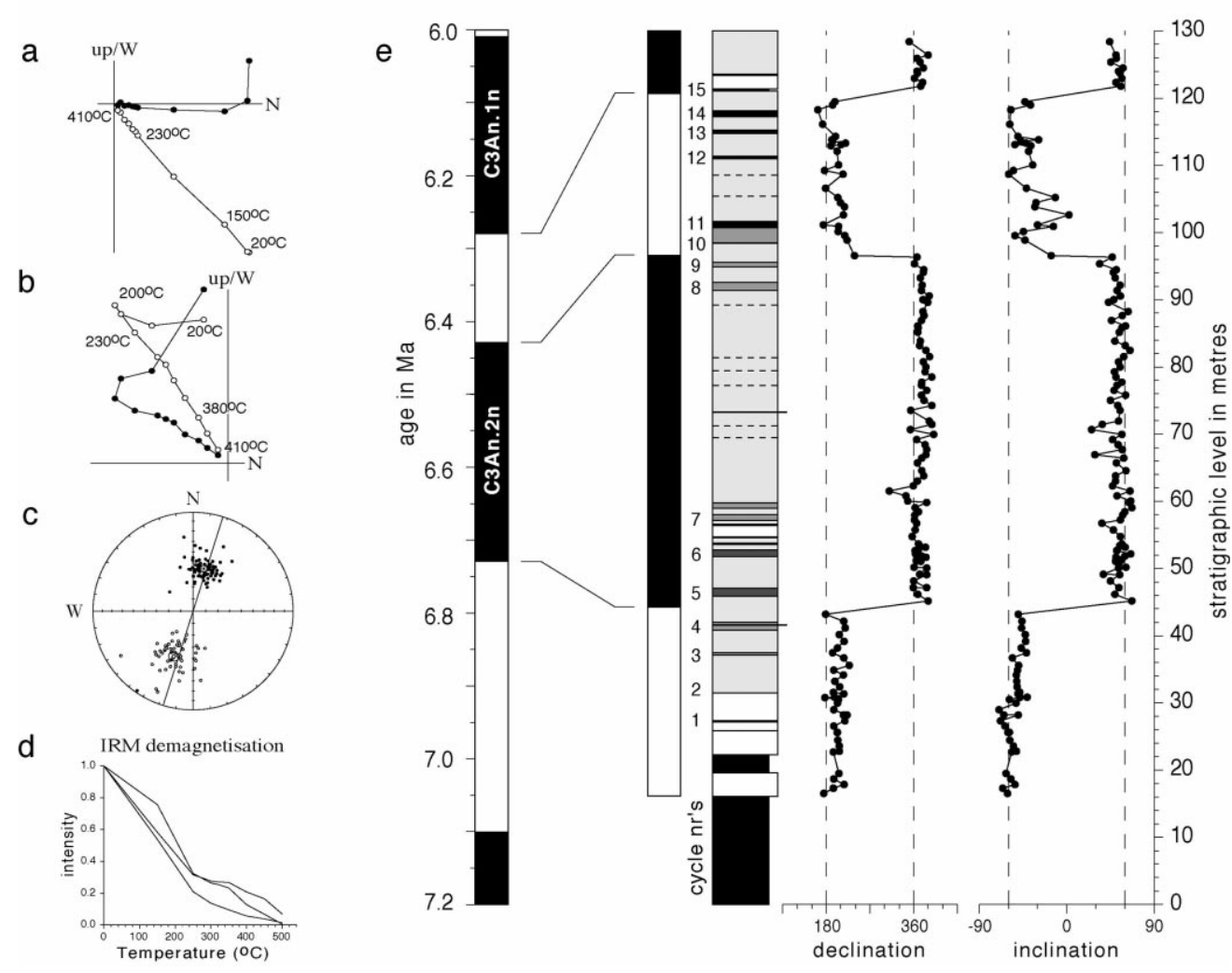

Fig. 4. a and b: Representative demagnetisation diagrams. c: Stereographic projection of palaeomagnetic directions: black (white) circles indicate downward (upward) projection. d: Thermal IRM demagnetisation. e: Palaeomagnetic directions of the Lava section and correlation of the polarity pattern to the constant spreading rate time scale [1]. For explanation of the lithological column, see Fig. 2.

struct a high-resolution chronology for the Lava section.

Thermal demagnetisation reveals a two-component NRM (Fig. 4a,b). The low-temperature (up to $200^{\circ} \mathrm{C}$ ) component generally has a random direction, but it may be approximately parallel to the present-day field in the slightly weathered uppermost part of the section. The characteristic remanent magnetisation (ChRM) is isolated above $200^{\circ} \mathrm{C}$ and shows both normal and reversed polarities. These normal and reversed ChRM directions are almost antipodal (Fig. 4c). Above $\sim 400^{\circ} \mathrm{C}$, both direction and intensity of the remanence change in many samples, indicating the presence of iron-sulphides (pyrite). To find the maximum unblocking temperatures, some samples were given an IRM that was thermally demagnetised. The samples have a maximum unblocking temperature of $500^{\circ} \mathrm{C}$ or higher, indicating magnetite (Fig. 4d).

The declinations and inclinations of the ChRM compose a well-defined magnetic polarity pattern in the Lava section, with two reversed and two normal intervals (Fig. 4e). Given the constraint that the mammal assemblage from Lava belongs to the lower part of MN13 [24], we find a unique correlation with the geomagnetic polarity time scale, in which the lower normal polarity interval represents $\mathrm{C} 3 \mathrm{An} .2 \mathrm{n}$, and the upper normal interval C3An.1n (Fig. 4e). 


\section{Astronomical forcing of the sedimentary cycles}

Recently, two new time scales have been proposed for the Messinian [1], one based on astronomical tuning of sedimentary cycles and one based on sea-floor spreading rates. Although the spreading rate (SR) ages are statistically indistinguishable from the astronomically tuned ages (APTS), there is a notable difference in the duration of the polarity intervals (Table 1). Based on the SR and APTS age models calculations were made for sedimentation rates and cycle periods (Table 1).

The APTS and SR ages are significantly older than those from previous time scales, which were based on marine magnetic anomaly spacings in the South Atlantic and on $\sim 10$ Myr spaced age calibration points [32,33]. These earlier time scales, for example CK95 [33], were presented 'pending further refinements such as the results of high-precision radiometric and astronomical dating methods', as stated by the authors. Since these refinements are now presented by Krijgsman and colleagues [1], we will not use the CK95 ages in this discussion, though for comparison, calculations based on these ages are listed in Table 1.

With the magnetostratigraphic time control, the average sedimentation rates in the two complete polarity zones in Lava can be calculated. As expected from other observations, the sedimentation rate in the lower interval is higher than in the upper interval. There is no reason to assume that the change in sedimentation rate co-occurs with a polarity reversal, in fact, it is probably located between 60 and $67 \mathrm{~m}$, where the change in both the thickness of the cycles and the average GR attenuation occurs (Fig. 2). We assume that the shift is located at $60 \mathrm{~m}$, because higher positions resulted in less consistent average cycle periods. The sedimentation rate for the reversed polarity zone was extrapolated downwards to $60 \mathrm{~m}$. This yields a new, virtual age control point, with which the average sedimentation rate for the lower part of the normal polarity zone is determined. The average sedimentation rate based on the SR age model arrives at $0.23 \mathrm{~m} / \mathrm{kyr}$ (Table 1). Extrapolation of the sedimentation rate using the

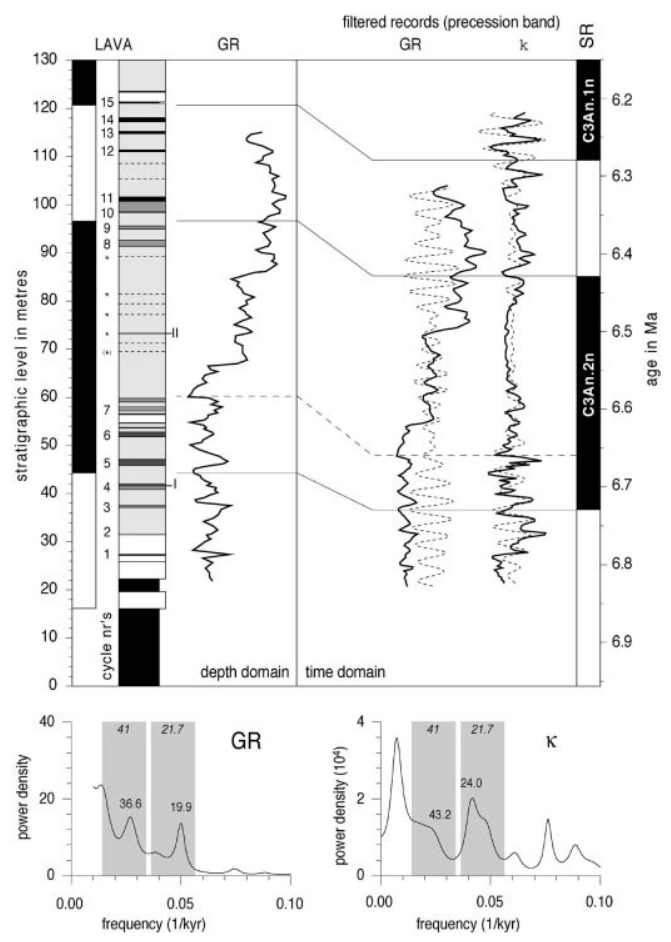

Fig. 5. Top: GR and $\kappa$ time series with their filtered components. The time series are generated from the SR ages for the reversals and our virtual age control point (see text), and re-sampled with $2.5 \mathrm{kyr}$ intervals. Cycles that were not expressed in the lithology, but were clearly present in the GR or $\kappa$ record, are indicated with an asterisk. For explanation of the lithological column, see Fig. 2. Bottom: Maximum entropy variance spectra of the GR (207 data points, length of filter is $12.8 \%$ of the series) and $\kappa$ ( 243 data points, length of filter is $11.2 \%$ of the series) time series, computed with the Analyseries program [27] and investigated in the frequency range $10^{-2}$ to $10^{-1}$ cycle/kyr. The shaded areas indicate the width of the obliquity and precession frequency bands, as used for the filtered precession components of the GR and $\kappa$ records. Numbers indicate cycle periods (kyr).

APTS age model leaves a negative amount of time for the lowermost part of the normal zone C3An.2n, and, therefore, an impossible sedimentation rate of $-2.2 \mathrm{~m} / \mathrm{kyr}$ (Table 1). Hence, only the calculations based on the SR age model will be used in the further discussion.

Combining the sedimentation rates from the SR age model with the average length of the sedimentary cycles in each interval results in an average duration for the cycles of $19.9 \pm 5.4$ to $23.0 \pm 3.1$ kyr for the thin sedimentary cycles, and $22.8 \pm 4.0$ 
kyr for the thick cycles (Table 1). The similarity of the periods of the thin and thick cycles suggests that the cycles are related to the same forcing mechanism. The average duration strongly suggests that the cycles were forced by precession.

The palynological data point to comparable changes in precipitation between the upper and lower cycles, and thus underline the hypothesis that the cycles are related to a single forcing mechanism. Palynological research on the Pliocene Ptolemais Formation suggested similar changes in precipitation for lignite-marl cycles [34], which were proven to be related to precession-controlled variations in regional climate $[16,17]$. This analogue between the palynological results from the Ptolemais and Lava cycles confirms our interpretation that sedimentary cycles in Lava were controlled by precession.

Spectral analysis of proxy records provides an objective estimate of periodic properties in time series of data. To be useful in testing the orbital hypothesis, the data must be transformed into a geological time series. We constructed GR and $\kappa$ time series by linear interpolation between and extrapolation beyond the control points, provided by - in our case - the SR ages of the palaeomagnetic reversals [1] and the extra age control point that we calculated for the $60 \mathrm{~m}$ level in the section (Table 1).

The variance spectra of the GR and $\kappa$ records vs. age are given in Fig. 5 (bottom). Both spectra reveal peaks in two frequency bands. The first frequency band includes periodicities close to the obliquity period of $41 \mathrm{kyr}$ and is located at 36.6 $\mathrm{kyr}$ in the GR and $43.2 \mathrm{kyr}$ in the $\kappa$ record. The second frequency band includes periodicities close to the precession periods of 23 and $19 \mathrm{kyr}$. A 19.9 kyr periodicity is present in the GR record and the $\kappa$ spectrum reveals a prominent peak at a period of $24.0 \mathrm{kyr}$. Further confirmation of cyclicity close to the mean of precession is given by applying a Gaussian bandpass filter to the GR and $\kappa$ records centred at $21.7 \mathrm{kyr}$ (Fig. 5, top). These results indicate that both the GR and $\kappa$ records, and thus the sedimentary cyclicity, have a strong orbital control that is dominated by precession and to a lesser extent by obliquity.

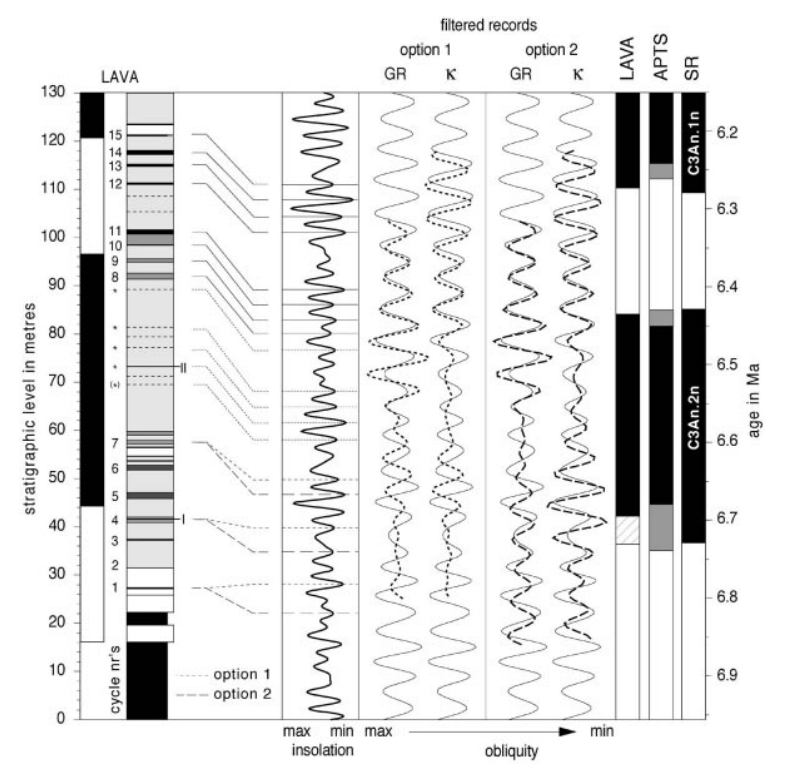

Fig. 6. Tuning of the sedimentary cycles in Lava to La90 $(1,1) 65^{\circ} \mathrm{N}$ summer (average of June and July) insolation [36]. For the correlation of the lower cluster (cycles $1-7)$, two options are indicated. Filtered GR and $\kappa$ records with a Gaussian bandpass filter centred around $41 \mathrm{kyr}$ are plotted on top of obliquity [36]. Two different age models were applied, according to the two correlation options of cycles $1-7$ in the Lava section. The filtered components are almost identical and in phase with obliquity in the upper part of the records. The first option results in negligible amplitude in the lowermost parts; the second option shows higher amplitudes, which are almost in phase with obliquity, and is thus preferred. The polarity pattern in the time domain is derived from our tuning and compared with the APTS and SR time scales [1].

\section{Astronomical tuning of the sedimentary cycles}

In the preceding section, we have shown that the sedimentary cycles are linked to dominantly precession-controlled variations in climate. Moreover, the pollen study has shown that the darkcoloured marl beds correspond to relatively dry periods, while the light-coloured marl beds correspond to more humid periods. In the Mediterranean area, relatively humid (and warm) climate occurred during summer insolation maxima, while the opposite regime occurred during insolation minima [35]. The dark-coloured marls can thus be correlated to insolation minima and the lightcoloured marls to insolation maxima.

Typical clusters of three-four cycles are ob- 
served in the upper part of the section (cycles 8 11 and 12-14) (Fig. 6). Considering that the individual sedimentary cycles are related to precession, those clusters represent maxima in $100 \mathrm{kyr}$ eccentricity cycle. With the upper two magnetic polarity reversals as approximate tie-points we can now tune these clusters to groups of highamplitude insolation cycles related to the eccentricity maxima at $\sim 6.4$ and $\sim 6.3 \mathrm{Ma}$ (Fig. 6 ).

Next, individual sedimentary cycles can be tuned to insolation. Cycle 11 has the most prominent organic-rich layer, and the underlying dark marl beds are alternatingly reduced and enhanced in GR and, to a lesser extent, $\kappa$. Therefore, cycle 11 is correlated to the high-amplitude minimum at 6.4 Ma, and the underlying cycles to consecutively older minima. The dark marls of cycles $12-14$ are very prominent; they are therefore correlated to the cluster of three high-amplitude insolation minima around 6.3 Ma.

In the middle of the section, no cycles were recognised in the lithology or in the $\kappa$ record. The GR record, however, showed several distinct maxima in this interval (Figs. 2 and 5), indicated by an asterisk in the stratigraphic column of Fig. 5. These cycles are correlated to a series of relatively high-amplitude insolation minima between 6.55 and $6.60 \mathrm{Ma}$, with the most prominent dark clay bed (key bed II) corresponding to the highest amplitude insolation minimum. The GR peak immediately below cycle 8 is very wide, and likely covers two cycles (see also filtered record, Figs. 2 and 5).

The cycles in the lower part of the section (1-7) show no typical clustering, and they can thus not be tuned using the eccentricity modulation of insolation. We can only use the position of the magnetic polarity transition as an approximate tiepoint. Therefore, there are two likely correlations for cycles 1-7 (Fig. 6). The first option uses the pronounced lithological expression of sedimentary cycles $5-7$ as starting point for the tuning. Cycles 5-7 are correlated to three consecutive insolation minima with slightly higher amplitudes than the minimum below $(\sim 6.71 \mathrm{Ma})$. Cycles $1-4$ are correlated to consecutive insolation minima. The second option correlates cycles 2-7 to one insolation cycle older, the prominent light-coloured carbo- nate bed of cycle 6 is correlated to the high-amplitude insolation maximum at $\sim 6.68$ and the carbonate-rich lithology of cycle 1 and below is correlated the high-amplitude insolation maximum at $\sim 6.79$ and $6.85 \mathrm{Ma}$.

The quality of the correlation can be tested by applying a Gaussian bandpass filter centred at 41 kyr to the GR and $\kappa$ records. Since the Lava record was tuned to the dominantly precession-related peaks of insolation, and thus independent of obliquity, a good fit between the filtered records and obliquity would suggest that the tuning is correct. The GR and $\kappa$ records were filtered for both tuning options (Fig. 6). The filtered components of both GR and $\kappa$ are almost identical in the uppermost part of the records, where the age models are identical, and they are in phase with obliquity, indicating that the tuning in this interval is correct. The lowermost parts of the two filtered records are clearly distinct: the first option (left-hand side in Fig. 6) results in negligible amplitude for the $41 \mathrm{kyr}$ component in this interval, so the phase cannot be compared; the second option (right-hand side in Fig. 6) results in a higher amplitude, and the cycles are almost in phase with obliquity. Therefore, we have a strong preference for the second correlation option.

We can now assign astronomical ages to the polarity reversals of the Lava section (Table 1). The positions of all the reversals are well-defined (Fig. 6 and Table 1), and the unambiguous astronomical tuning of cycles $8-15$ results in high-precision ages for the C3An.2n(y) and C3An.1n(o) reversals (Fig. 6). The two correlation options for cycles 1-7 result in two possible astronomical ages for reversal C3An.2n(o) (Fig. 6), the older of which is preferred. Comparison with the APTS ages shows that all our reversals are within the error limits of the APTS ages, but have a higher precision (Table 1). The SR ages of the upper two reversals cannot be distinguished from our astronomical ages; the SR age of the lower reversal is within the error limits of our preferred tuned age.

\section{Conclusions}

A reliable magnetostratigraphy is established 
for the Messinian Lava section, which results in an age of $\sim 6.9 \mathrm{Ma}$ for the base and $\sim 6.2 \mathrm{Ma}$ for the top of the section. The cycles in the Lava section, as expressed in the lithology, gamma-ray attenuation and susceptibility records have the same duration and are forced by precession. Palynological data indicate that dark marls were deposited during summer insolation minima (dryer periods with cooler summers), and light marls in maxima (more humid periods with warmer summers). Astronomical tuning of the cycles yields absolute ages for the polarity reversals that confirm and define more precisely the APTS ages of Krijgsman and colleagues [1].

\section{Acknowledgements}

Constantin Doukas (University of Athens, Greece) is greatly acknowledged for arranging necessary contacts and for co-operation in the field. We are grateful to the Larko Mining Corporation for permission to work in their quarry and the corporation's employees for their hospitality and assistance in the field. The authors thank Wout Krijgsman, Johan Meulenkamp, Rob Satter, Erik Snel and Konstantin Theocharopoulos for various discussions and assistance in the field. We thank Cor Langereis, Johan Meulenkamp and Henk Visscher and the reviewers R.H. Benson and H. Pälike for their valuable comments. The investigations were supported by the Netherlands Council for Earth and Life Sciences (ALW), part of the Netherlands Science Foundation (grant to J.S., M.L.K.-v.H. and N.v.V.).[R $\boldsymbol{V}]$

\section{References}

[1] W. Krijgsman, F.J. Hilgen, I. Raffi, F.J. Sierro, D.S. Wilson, Chronology, causes and progression of the Messinian salinity crisis, Nature 400 (1999) 652-655.

[2] M. Milankovitch, Kanon der Erdbestrahlung und seine Anwendung auf das Eiszeitenproblem, R. Serb. Acad. Spec. Publ. 133 (1941) 1-633.

[3] C. Emiliani, Pleistocene temperatures, J. Geol. 63 (1955) $538-578$.

[4] N.J. Shackleton, N.D. Opdyke, Oxygen isotope and pa- leomagnetic stratigraphy of Pacific core V28-238 oxygen and isotope temperatures and ice volumes on a 105 and 106 year scale, Quat. Res. 3 (1973) 39-55.

[5] J.D. Hays, J. Imbrie, N.J. Shackleton, Variations in the Earth's orbit pacemaker of the ice ages, Science 194 (1976) 1121-1132.

[6] J. Imbrie, J.D. Hays, D.G. Martinson, A. McIntyre, A.C. Mix, The orbital theory of Pleistocene climate: support from a revised chronology of the marine $\delta^{18} \mathrm{O}$ record, in: A. Berger, J. Imbrie, J. Hays, G. Kukla, B. Saltzman (Eds.), Milankovitch and Climate, Reidel, Dordrecht, 1984, 510 pp.

[7] L.J. Lourens, A. Antonarakou, F.J. Hilgen, A.A.M. Van Hoof, C. Vergnaud-Grazzini, W.J. Zachariasse, Evaluation of the Plio-Pleistocene astronomical timescale, Paleoceanography 11 (1996) 391-413.

[8] F.J. Hilgen, W. Krijgsman, C.G. Langereis, L.J. Lourens, Breakthrough made in dating of the geological record, EOS Trans. AGU 78 (1997) 285-289.

[9] N.J. Shackleton, S.J. Crowhurst, Sediment fluxes based on an orbitally tuned time scale $5 \mathrm{Ma}$ to $14 \mathrm{Ma}$, Site 926, Proc. Ocean Drill. Prog. Sci. Res. 154 (1997) 69-82.

[10] N.J. Shackleton, S.J. Crowhurst, G.P. Weedon, J. Laskar, Astronomical calibration of Oligocene-Miocene time, Philos. Trans. R. Soc. Lond. A 357 (1999) 1907-1929.

[11] R.H. Benson, L.-A.C. Hayek, D.A. Hodell, K. Rakic-ElBied, Extending the climatic precession curve back into the late Miocene by signature template comparison, $\mathrm{Pa}$ leoceanography 10 (1995) 5-20.

[12] W. Krijgsman, F.J. Hilgen, C.L. Langereis, W.J. Zachariasse, The age of the Tortonian-Messinian boundary, Earth Planet. Sci. Lett. 121 (1994) 533-547.

[13] P.E. Olsen, D.V. Kent, Milankovitch climate forcing in the tropics of Pangea during the Late Triassic, Palaeogeogr. Palaeoclimatol. Palaeoecol. 122 (1996) 1-26.

[14] D.V. Kent, P.E. Olsen, Astronomically tuned geomagnetic polarity timescale for the Late Triassic, J. Geophys. Res. 104 (1999) 12,831-12,841.

[15] H. Abdul Aziz, F.J. Hilgen, W. Krijgsman, E. Sanz, J.P. Calvo, Astronomical forcing of sedimentary cycles in the Miocene continental Calatayud Basin (NE Spain), Earth Planet. Sci. Lett. 177 (2000) 9-22.

[16] N. van Vugt, J. Steenbrink, C.G. Langereis, F.J. Hilgen, J.E. Meulenkamp, Magnetostratigraphy-based astronomical tuning of the early Pliocene lacustrine sediments of Ptolemais (NW Greece) and bed-to-bed correlation with the marine record, Earth Planet. Sci. Lett. 164 (1998) 535 551.

[17] J. Steenbrink, N. van Vugt, F.J. Hilgen, J.R. Wijbrans, J.E. Meulenkamp, Sedimentary cycles and volcanic ash beds in the lower Pliocene lacustrine succession of Ptolemais (NW Greece): Discrepancy between 40Ar/39Ar and astronomical ages, Palaeogeogr. Palaeoclimatol. Palaeoecol. 152 (1999) 283-303.

[18] N. van Vugt, Orbital forcing in late Neogene lacustrine basins from the Mediterranean, Thesis, Utrecht University, 2000, 168 pp. 
[19] IGME, Geological map of Greece, sheet 62, Ptolemais, 1997.

[20] J.H. Brunn, Contribution à la geologie du Pinde septentrional et de la Macédoine occidentale, Ann. Géol. Pays Hellen 7 (1956) 1-413.

[21] S.B. Pavlides, D.M. Mountrakis, Extensional tectonics of northwestern Macedonia, Greece, since the late Miocene, J. Struct. Geol. 9 (1987) 385-392.

[22] E. Ehlers, Bericht über die bisher im Rahmen der Expertise Ptolemais durchgeführten geologischen und paläontologischen Untersuchungen, Archiv Bundesanst. Geowiss. and Rohst., Hannover, internal report, number 66464, 1960.

[23] J. Anastopoulos, C.N. Koukouzas, Economic geology of the southern part of the Ptolemais lignite basin (Macedonia, Greece), Geol. Geophys. Res. 16 (1972) 1-189.

[24] H. de Bruijn, G. Saraç, L. van den Hoek Ostende, S. Roussiakis, The status of the genus name Parapodemus Schaub, 1938; new data bearing on an old controversy, Deinsea 7 (1999) 95-112.

[25] E. Velitzelos, H.J. Gregor, Some aspects of the Neogene floral history in Greece, Rev. Palaeobot. Palynol. 62 (1990) 291-307.

[26] P.A. Antoniadis, E. Rieber, Zum Fossilinhalt, Kohlegenese und Stratigraphie des Kohlebeckens von Lava in Nordgriechenland, Acta Palaeobot. 37 (1997) 61-80.

[27] D. Paillard, L. Labeyrie, P. Yiou, Macintosh program performs time-series analysis, Eos Trans. AGU 77 (1996) 379.

[28] E. Velitzelos, H.-J. Gregor, Geologische Daten zu den fossilführenden Fundstellen Lava, Prosilion und Likudi (Griechenland) nebst Bemerkungen $\mathrm{zu}$ deren Fruchtund Samenfloren, Duc. Nat. 29 (1986) 34-40.

[29] J.H. ten Veen, G. Postman, Astronomically forced variations in gamma-ray intensity: Late Miocene hemipelagic successions in the eastern Mediterranean basin as a test case, Geology 24 (1996) 15-18.

[30] A. Farjon, Pinaceae, drawings and descriptions of the genera, Koeltz Scientific Books, Königstein, 1990, 330 pp.

[31] W. van Zeist, S. Bottema, Vegetational history of the eastern Mediterranean and the Near East during the last 20.000 years, in: J.L. Bintliff, W. van Zeist (Eds.), Palaeoclimates, Palaeoenvironments and Human Communities in the Eastern Mediterranean Region in Later Prehistory, BAR Int. Ser. 133 (II) (1982) 277-321.

[32] S.C. Cande, D.V. Kent, A new geomagnetic polarity time scale for the Late Cretaceous and Cenozoic, Geophys. Res. Lett. 97 (1992) 13917-13951.

[33] S.C. Cande, D.V. Kent, Revised calibration of the geomagnetic polarity time scale for the Late Cretaceous and Cenozoic, Geophys. Res. Lett. 100 (1995) 6093-9095.

[34] M.L. van Hoeve, J. Steenbrink, N. van Vugt, J.E. Meulenkamp, Biotic and abiotic response to orbital forcing in different frequency bands, Terra Nostra 98 (1998) 49-55.

[35] E.J. Rohling, F.J. Hilgen, The eastern Mediterranean climate at times of sapropel formation: a review, Geol. Mijnb. 70 (1991) 252-264.

[36] J. Laskar, The chaotic motion of the solar system: A numerical estimate of the size of the chaotic zones, Icarus 88 (1990) 266-291. 